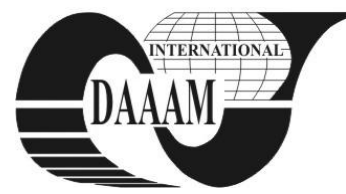

Annals of DAAAM for 2011 \& Proceedings of the 22nd International DAAAM Symposium, Volume 22, No. 1, ISSN 1726-9679 ISBN 978-3-901509-83-4, Editor B. Katalinic, Published by DAAAM International, Vienna, Austria, EU, 2011 Make Harmony between Technology and Nature, and Your Mind will Fly Free as a Bird Annals \& Proceedings of DAAAM International 2011

\title{
ORGANIZATION OF E-LEARNING COURSE
}

\author{
RUTAR, A[na] \& MESTROVIC, D[ubravka]
}

\begin{abstract}
Development of e-learning content is a long process and requires considerable initial effort. Depending on the complexity of the e-learning content, its creation could require much longer than the one intended for the educational process in the actual classroom. Actually, creating the e-learning lessons is time consuming, regardless wheather it is online or not. Good organization can make production, modification and content correction easier.
\end{abstract}

Key words: e-learning, planning, scenarios, templates, development

\section{INTRODUCTION}

Due to the rapid progress of technology there is the need to constantly learn new things. E-learning is becoming more widespread. There are many advantages for students, for teachers and for organizations willing to educate their employees. Students themselves choose when, where and what they learn and they can choose their own learning pace. Teachers can use e-learning as a method of teaching preparation or as a teaching tool. Organizations can use e-learning for consistent, timeless and quality training of employees around the world (Horton, 2011). However, the development of e-learning content is a long process. Moreover let's not forget that it requires a large initial effort. Its mere creation can be a very complicated process itself. Generally, to make high quality e-learning content you need: good lesson planning, knowledge of basic principles of learning and knowledge of educational materials as well as students (Piskurich, 2000). But the organization of the whole process lies in the first place. Therefore, every time saving stage in this process of content development is welcomed. If development costs are reduced, saved money can be invested in new e-learning courses and make e-learning education even more accessible.

\section{ORGANIZATION OF AN E-LEARNING COURSE}

\subsection{Templates}

Significant time savings in creating e-learning content can be achieved by using templates. Templates are partially completed components containing invariable and variable parts. Invariable parts contain: logos, navigation buttons, headers, footers, and other elements that occuor repeatedly in many elearning lessons. Variable parts can be edited and they can be different in each lesson. For example, they may be empty, filled with text or with inserted elements.

The main advantage of using templates is that their usage preserves the quality and consistency of appearance (Fee, 2009). They also accelerate the development of the e-learning course, because many of the elements are created only once. To create quality templates specific standards need to be defined. These standards relate to the style and font size, placement of certain objects in the template, the colors that will be used, page layouts, size and placement of icons.
Figure (1) shows template for the lesson which will be developed in Adobe Captivate. Different types of text boxes highlight boxes and buttons are prepared and they are ready to be used in the lessons.

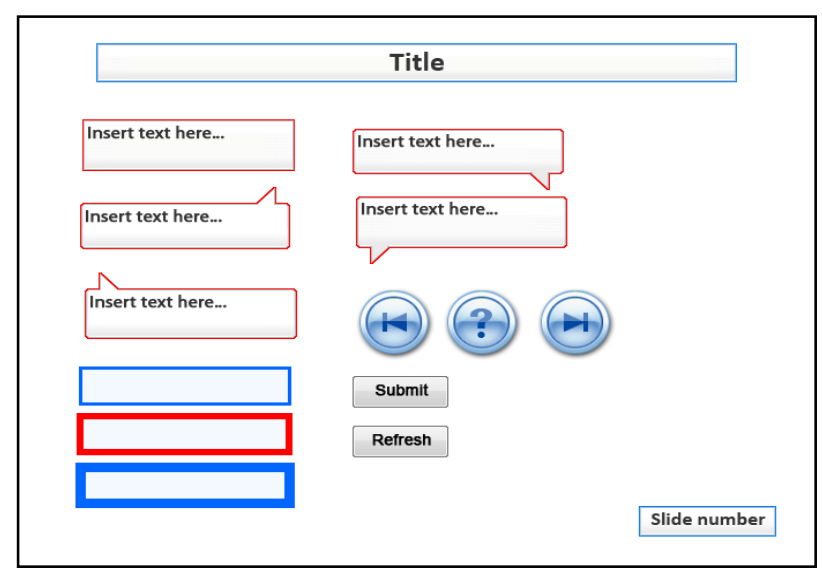

Fig. 1. Template for a lesson

\subsection{Scenarios}

Templates can be used for different scenarios, e.g one template for introduction of the lessons and the other one for further exercises. For example each scenario for each lesson should have an introduction, motivational part, presentation of materials, exercises and a conclusion. When creating a scenario we must have in mind that each lesson should state what exactly students will accomplish in the lesson, what they will learn from each lesson and why it is important to learn that part of the curriculum. The material must be presented in a simple way and we should create exercises where students can practice the content learned.The conclusion in the end is used to revise important concepts and to emphasize the importance of the task. Scenarios should not be too complicated, but they must be accurate and precise. The scenario defines actions needed to create a lesson (Allan Michael, 2003). Figure (2) shows an example of a scenario written in MS Word.

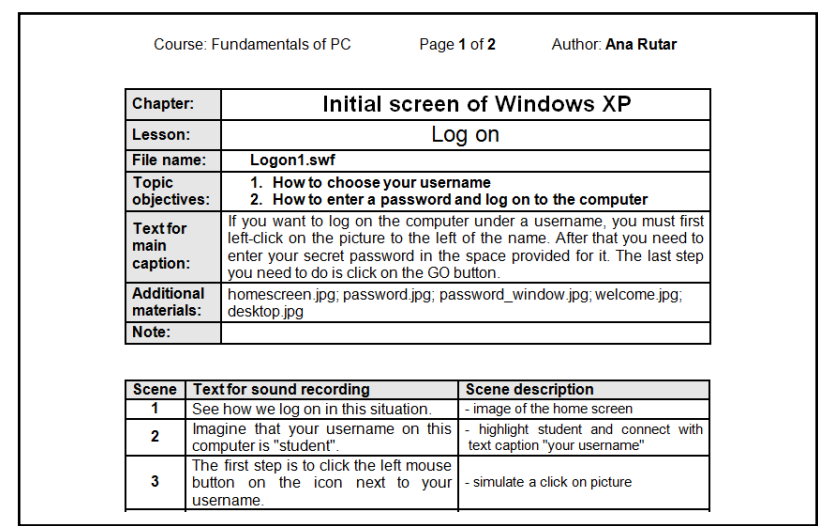

Fig. 2. Scenario about logon to computer in Windows XP 
Scenarios are usually used when more people participate in the development of the e-learning lessons, where one of them writes a scenario with the content and descriptions of the lessons, while others develop the lesson by one of the software tools. They enable the task division in development stage of elearning content depending on the knowledge of the participants. It furthermore means that the developers of e-learning lessons in one of the software may not be familiar with the content itself. In this way, scenarios are the easier choice for creators of e-learning lessons; they enable collaboration with experts from different fields and do not require further or extra education before the development (Gagne et al., 2005).

\subsection{Writing reports}

Courses can often contain up to tens or even hundreds of lessons. They can be in various stages of development: editing, finished, waiting for audio insertion etc. A very important issue when developing e-learning content is writing reports. The reports may contain a list of all the lessons in the course, information about the stage of development, the program's name in which it is created, the information about sound or other multimedia elements. This information is useful in the development of e-learning because reports show the number of lessons that have been made and even estimate the duration of a certain stage of the course development. Writing reports is very important if the e-learning lessons are developed by a team. Figure (3) shows an example of the structure of MS Word elearning course. The document shows the names of the chapters and lessons, the program's name in which the lesson has been created, the information about the sound and the stage of development.

\begin{tabular}{|c|c|c|c|c|c|}
\hline 4 & A & B & c & D & E \\
\hline 1 & $\begin{array}{l}\text { COURS MS WORD: } \\
\text { UNIT AND LESSON NAMES }\end{array}$ & $\begin{array}{c}\text { TOOL FOR } \\
\text { CONTENT } \\
\text { ELABORATION }\end{array}$ & \begin{tabular}{|c|} 
DOES IT \\
INCLUDE THE \\
SOUND \\
$?$ \\
\end{tabular} & $\begin{array}{l}\text { sound } \\
\text { (kbps) }\end{array}$ & STATUS \\
\hline 2 & 1. Using Aplication & & & & \\
\hline 3 & 1.1. Basic Operations & & & & \\
\hline 4 & Introduction & Engage & no & & finished \\
\hline 5 & Program Start & Captivate & yes & 64 & finished \\
\hline 6 & Quick Program Start & Captivate & yes & 64 & waiting for sound record \\
\hline 7 & User interface layout & Engage & no & & waiting for proofreading \\
\hline 8 & Ribbons - appearance & Engage & no & & finished \\
\hline 9 & Ribbons - customization & Captivate & yes & 64 & pending review 1 \\
\hline 10 & $\begin{array}{ll}\text { Contextual Tools } \\
\end{array}$ & Engage & no & & pending review 1 \\
\hline 11 & Displaying Rulers & Captivate & no & 64 & pending final review \\
\hline 12 & Closing Program & Captivate & yes & 64 & waiting for sound record \\
\hline 13 & Useful Tips & Engage & no & & $0 \%$ \\
\hline 14 & Summary & Engage & no & & $0 \%$ \\
\hline
\end{tabular}

Fig. 3. Structure MS Word e-learning course

\subsection{Organization of folder structure}

During the development of each e-learning lesson, many different files are created. These are, for example, files created in tools for the content creation, audio, video and images, files that are built into lessons, scenarios, files created after publishing of the lesson, etc. If we multiply the number of lessons and the number of created files, results are often a few hundreds or thousands of files. If all the files on the computer are saved into one folder, it would be impossible to manage. Developers can waste a lot of time while looking for images and documents if they are not stored away properly. Different files that are generated when publishing a lesson could have the same name and cannot be stored in the same folder. It is necessary to create the folder structure on your computer where your files are to be stored. Well planned folder structure makes easy to search for and access the files in the process of development and during the changes of lessons. If one developer needs to work on some other developer's files, consistent file structure saves time (Curry, 2009). It's a good practise to group the same type of files in the shared folders. For example, we can create a common folder for images of the entire course or a separate folder with pictures inside each chapter or lesson.
It is good to name the folder according to its contents. Naming such folders as folder1, folder2, folder3 is not advised and it is preferable to give them names like Images, Source, Sound, Published_files, etc. Figure (4) shows an example of the structure of the course „MS Word" in which each chapter folder contains special subfolders for images, sound files, scenarios, used examples and files created in different programs.

\begin{tabular}{|c|}
\hline 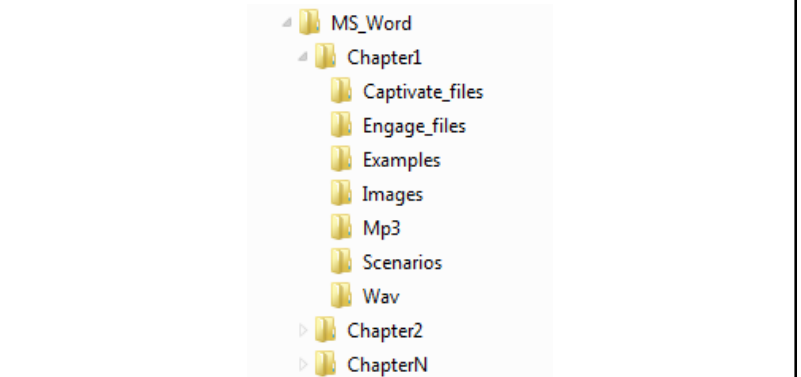 \\
\hline
\end{tabular}

Fig.4. Example of folder structure

\subsection{Backup}

Due to the various unforeseen situations such as lightning, computer failure, hacking, etc. weeks or even months of work could be lost. It is therefore very important to make backup copies of the e-learning lessons. Copies of e-learning lessons should be kept on different computers, and preferably at different locations. In addition it is important to update backup copies regularly (figure 5).

\begin{tabular}{|l|}
\hline J3 MS_WORD \\
MS_WORD_BACKUP_2011_05_01 \\
MS_WORD_BACKUP_2011_05_15 \\
MS_WORD_BACKUP_2011_06_01 \\
\hline
\end{tabular}

Fig. 5. Course backup folders

\section{CONCLUSION}

In development of e-learning content, we use all of the above time savers. However, some e-learning developers use only reports, others use only templates and scenarios. Generally, using templates, scenarios, good organization of the folder structure, backup of the course materials and writing reports are just some examples how good organization can speed up the work, reduce the possibility of errors, and save time and money. In the future we plan to spend more time studying new tools for e-learning content creation, to see if maybe some of them require less time for content creation than programs we currently use.

\section{REFERENCES}

Allan Michael, W. (2003). Guide to E-learning, John Wiley and Sons Inc., ISBN 0-471-20302-5, New Jersey

Curry, S. \& associates (2009). 65 Tips for Getting the Most Out of Your e-Learning Budget, Brandon, B. (Ed), The eLearning Guild, Available from: http://www.elearningguild.com/ Accessed: 2011-06-02

Fee, K. (2009). Delivering E-Learning: A Complete Strategy for Design, Application and Assessment, Kogan Page, ISBN 978-0-7494-5397-8, London

Gagne, R. M. \& associates (2005). Principles of Instructional Design, Wardsworth/Thomson Learning, ISBN 0-534-582842, Belmont

Horton, W. (2011). e-Learning by Design, 2nd Edition, John Wiley \& Sons, ISBN: 978-0-470-90002-4, New York

Piskurich, G. M. (2000). Rapid Instructional Design, JoseyBass/Pfeiffer, ISBN 0-7879-8073-0, San Francisco 